\title{
Microwave-assisted hydrothermal synthesis followed by heat treatment: A new route to obtain $\mathrm{CaZrO}_{3}$
}

\author{
Wagner D. Macedo Jr. ${ }^{\mathrm{a}, *}$, Agda E. Souza ${ }^{\mathrm{a}}$, Gleyson T.A. Santos ${ }^{\mathrm{a}}$, Silvio R. Teixeira ${ }^{\mathrm{a}}$, Elson Longo \\ a São Paulo State University (UNESP), Dept. of Physics, Presidente Prudente, São Paulo 19060-900, Brazil \\ b Federal University of São Carlos (UFSCar), CDMF/CEPID, São Carlos, São Paulo 13565-905, Brazil
}

\section{A R T I C L E I N F O}

\section{Keywords:}

Hydrothermal

Microwave

Heat treatment

$\mathrm{CaZrO}_{3}$

\begin{abstract}
A B S T R A C T
$\mathrm{CaZrO}_{3}$ nanoparticles were obtained by a new synthesis route: nucleation using the microwave-assisted hydrothermal method (MAH) and crystallization by heat treatment. Structural characterization by X-ray diffraction (XRD) was performed for the synthesized material and after heat treatment at 700, 800, 900, 1000 and $1200{ }^{\circ} \mathrm{C}$. At $800{ }^{\circ} \mathrm{C}$, the lakargite phase crystallization $\left(\mathrm{CaZrO}_{3}\right)$ starts and portions of the non-stoichiometric calciumzirconium oxide phase were observed by XRD and Raman spectroscopy. A residual $\mathrm{CaCO}_{3}$ phase was present in the untreated samples. At $1200{ }^{\circ} \mathrm{C}$, the well-crystallized stoichiometric and non-stoichiometric mixed oxide phases of $\mathrm{CaZrO}_{3}$ (crystallites of about $75 \mathrm{~nm}$ ) were observed, along with particle agglomerates often in the micrometer range. The synthesized material was subjected to differential thermal analysis, which revealed carbonate degradation at approximately $695{ }^{\circ} \mathrm{C}$, resulting in a small loss of mass of $6 \%$. An endothermic reaction at $85^{\circ} \mathrm{C}$ was observed for water loss, where there was a considerable amount of energy involved. This result showed the sensitivity to moisture absorption and adsorption processes of the $\mathrm{CaZrO}_{3}$ sample, obtained by the MAH route. UV-Vis spectroscopy showed the characteristic gap energies for the two phases, which were 2.9 (non-stoichiometric) and $4.9 \mathrm{eV}$ (stoichiometric), values smaller than those obtained by usual synthesis routes.
\end{abstract}

\section{Introduction}

Calcium zirconate $\left(\mathrm{CaZrO}_{3}\right)$ is a perovskite family ceramic, whose mineral in its natural form was only discovered in 2008 in the northern part of the Caucasus region, Russia [1]. This material shows polymorphic transition from orthorhombic to cubic at $1750^{\circ} \mathrm{C}$, has a relatively small thermal expansion coefficient and high thermal and chemical stability [2]. At room temperature, its orthorhombic structure exhibits slightly deformed $\left[\mathrm{ZrO}_{6}\right]$ and $\left[\mathrm{CaO}_{8}\right]$ clusters (Fig. 1), which may generate intermediate states in the energy gap of the material, affecting its optical properties [3].

$\mathrm{CaZrO}_{3}$ has very interesting electrical properties, potentiating its use in various applications, mainly as a humidity sensor [5]. Dudek et al. [6] reported the sensor properties of a $\mathrm{CaZrO}_{3}-\mathrm{CaO}-\mathrm{ZrO}_{2}$ system, obtained by different synthesis methods with subsequent thermal treatments at temperatures between 1000 and $1500{ }^{\circ} \mathrm{C} . \mathrm{CaZrO}_{3}$ can be used as a semiconductor, with applications in high-temperature water sensors, photoluminescent emitter at 450 and $700 \mathrm{~nm}$, solid electrolyte, proton conductor and photocatalytic material (for molecules such as rhodamine B) [5-10]. In addition, $\mathrm{CaZrO}_{3}$ can be used in various areas due to its refractory character (melting point of $2340{ }^{\circ} \mathrm{C}$ ), relative high electrical permittivity and low dissipation factor [11].

Stoichiometric $\mathrm{CaZrO}_{3}$ has been reported as a p-type semiconductor material. When small excesses of $\mathrm{CaO}$ or $\mathrm{ZrO}_{2}$ are added to $\mathrm{CaZrO}_{3}$, ionic conductivity is observed for different values of oxygen partial pressure besides high chemical stability at temperatures above $1000{ }^{\circ} \mathrm{C}$. Therefore, $\mathrm{CaZrO}_{3}-\mathrm{ZrO}_{2}$ heterostructure can be beneficial for both ionic conduction and improvements in water adsorption due to its increased surface area [12].

There are several physical or chemical methods for obtaining this material, such as the polymer precursor, or Pechini method [13], sol-gel [14], gelation-combustion [15], solid state reaction [16] and microwave-assisted salt melting [17]. However, there are no reported studies on the synthesis of this material by microwave-assisted hydrothermal methods (MAH) [18]. In this work, $\mathrm{CaZrO}_{3}$ nanoparticles were nucleated using MAH and subsequently thermally treated to complete the $\mathrm{CaZrO}_{3}$ phase crystallization. A new method for the synthesis of this ceramic allows us to investigate new microstructures and possibly improve their properties, especially those concerning applications in humidity sensors [19].

\footnotetext{
* Correspondence to: Roberto Simonsen, 305, Presidente Prudente, São Paulo 19060-900, Brazil.

E-mail address: snow_dias@hotmail.com (W.D. Macedo).
} 


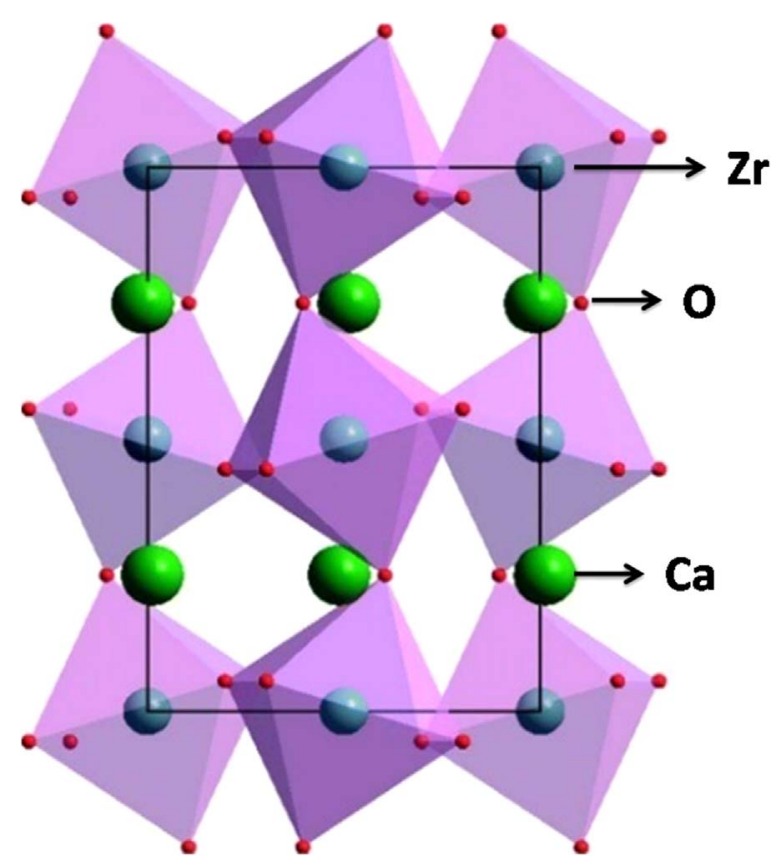

Fig. 1. $\left[\mathrm{ZrO}_{6}\right]$ and $\left[\mathrm{CaO}_{8}\right]$ clusters slightly deformed in the $\mathrm{CaZrO}_{3}$ orthorhombic structure [4].

\section{Experimental procedure}

$\mathrm{CaZrO}_{3}$ nanoparticles were produced in two processing steps. In the first, we used MAH with a heating rate of $140{ }^{\circ} \mathrm{C} / \mathrm{min}$, temperature of $140{ }^{\circ} \mathrm{C}$, synthesis times of 20 and $160 \mathrm{~min}$ and maximum pressure of 4 bar. The precursor solution was prepared in deionized water by adding, with stirring, $\mathrm{CaCl}_{2} \cdot 2 \mathrm{H}_{2} \mathrm{O}$ (99\%, Synth), $\mathrm{ZrOCl}_{2} \cdot 8 \mathrm{H}_{2} \mathrm{O}(99 \%$, Synth) and $\mathrm{NaOH}(6 \mathrm{~mol} / \mathrm{L})(98 \%$, Synth) as a mineralizing agent. The chlorides were stoichiometrically mixed at a $0.01 \mathrm{~mol} \mathrm{Ca} / \mathrm{Zr}$ ratio. After the synthesis, the supernatant was discarded and the ceramic precipitate was washed several times with deionized water until neutral $\mathrm{pH}$ [20]. The material thus synthesized was dried in an oven, ground in an agate mortar and then subjected to structural characterization. In the second stage, the samples were subjected to thermal treatments at 700 , $800,900,1000$ and $1200{ }^{\circ} \mathrm{C}$ for $1 \mathrm{~h}$, using a laboratory furnace (EDG 3000). To evaluate the effect of heating time, a sample was treated at $1000{ }^{\circ} \mathrm{C}$ for $6 \mathrm{~h}$.

Identification of the phases in the samples was performed by X-ray diffraction (XRD) analysis (Shimadzu XRD-6000), with $\mathrm{Cu} K \alpha 1(\lambda=$ $1.5406 \AA$ ) and $\mathrm{Cu} \mathrm{K \alpha} 2(\lambda=1.5444 \AA)$, at $40 \mathrm{kV}$ and $30 \mathrm{~mA}$, with $0.02^{\circ}$ step, scanning speed of $2^{\circ} / \mathrm{min}$ and angular range $2 \theta=10^{\circ}$ to $80^{\circ}$. Also, data were collected for structure refinement using the Rietveld method, for the $\mathrm{CaZrO}_{3}$ sample heated at $1200{ }^{\circ} \mathrm{C}$. In this case, the angular range (20) was from $10^{\circ}$ to $120^{\circ}$, with scanning speed of $0.2^{\circ} / \mathrm{min}$. The average crystallite size of some samples was calculated using the Scherrer equation (Eq. (1)), using XPowder software, where background and $k \alpha 2$ radiation were subtracted. In this equation, $D$ is the average crystallite size, $k$ is a dimensionless constant called the form factor (Scherrer constant, which varies with the geometric configuration of the crystallite), $\lambda$ is the wavelength of the radiation ( $\mathrm{Cu} k \alpha 1), \theta$ is the diffraction angle, and $\beta$ is the full width at half maximum (FWHM) of the most intense diffraction peak [21].

$D=k \lambda / \beta \cos \theta$

Thermal characterization was performed by differential scanning calorimetry (DSC) and thermogravimetry (TG) (SDT-Q600TA Instruments). The analyses were carried out up to $1200^{\circ} \mathrm{C}$, at a heating rate of $10^{\circ} \mathrm{C} / \mathrm{min}$ in air flow $(100 \mathrm{~mL} / \mathrm{min})$. The morphology of the synthesized $(160 \mathrm{~min})$ and heated sample $\left(1000{ }^{\circ} \mathrm{C}, 1 \mathrm{~h}\right)$ were

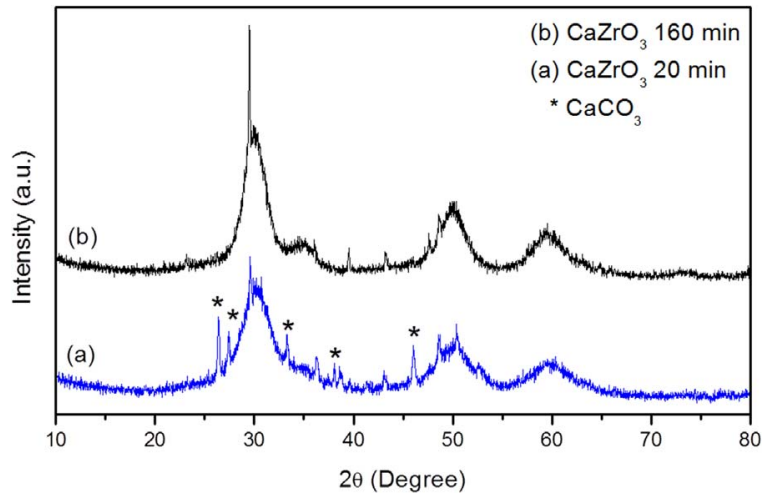

Fig. 2. XRD of the $\mathrm{CaZrO}_{3}$ samples synthesized for (a) $20 \mathrm{~min}$ and (b) $160 \mathrm{~min}\left(140{ }^{\circ} \mathrm{C}\right)$ using MAH method.

characterized using a scanning electron microscope (SEM, Supra ${ }^{\mathrm{TM}} 35$ Gemini, Zeiss).

The synthesized sample (MAH) at $160 \mathrm{~min}$ and treated $\left(1200^{\circ} \mathrm{C}\right.$, $1 \mathrm{~h}$ ) was analyzed directly in the powder form at room temperature using Raman scattering and UV-Vis absorption. Raman spectroscopy was performed using a Renishaw micro-Raman, inVia model, equipped with Leica microscope and CCD detector. Raman spectra were obtained with scanning from 100 to $600 \mathrm{~cm}^{-1}$, with a $514 \mathrm{~nm}$ wavelength excitation laser (He-Ne). Finally, UV-Vis spectroscopy was performed by diffuse reflectance (Cary $5 \mathrm{G}$ Varian) spectrophotometer (UV-Vis-NIR) in full reflection mode. The equipment was calibrated with two Labsphere reflectance standards, SRS 94-010 (white, 99\% reflection) and SRD 02-010 (black, $0.2 \%$ reflection). The region analyzed was 800-200 nm with a $600 \mathrm{~nm} / \mathrm{min}$ step and a lamp change (visible - ultraviolet) at $350 \mathrm{~nm}$. The gap energy $\left(\mathrm{E}_{\text {gap }}\right)$ was estimated using the Wood and Tauc method [22].

\section{Results and discussion}

The X-ray diffractograms of samples synthesized by MAH for 20 and $160 \mathrm{~min}$ (Fig. 2) showed wide peaks (at $30^{\circ}, 50^{\circ}$ and $60^{\circ}, 2 \theta$ ). This particular characteristic of wide peaks is related to the short- and medium-range order of the ceramic material structure, indicating a process of phase nucleation. The wide peak between $20^{\circ}$ and $40^{\circ}(2 \theta)$, with a maximum of $30^{\circ}$, is characteristic of the medium-range order of a glass structure. These three peaks are located in the positions of the most intense peaks of non-stoichiometric calcium-zirconium oxide. The peak near $2 \theta=30^{\circ}$ corresponds to the calcium zirconate phase. In addition, calcium carbonate formation $\left(\mathrm{CaCO}_{3}-\mathrm{PDF}\right.$ 5-0586) can be observed, mainly for the sample prepared with less synthesis time (20 min). In this case, it can be concluded that the MAH method used provides energy for the crystallite nucleation process, but that it is not sufficient for phase growth.

Fig. 3 shows the thermal analysis results of the oven-dried $\mathrm{CaZrO}_{3}$ ceramic powder, synthesized by MAH for $20 \mathrm{~min}$. The endothermic peak at $85{ }^{\circ} \mathrm{C}$ showed a mass loss of $8 \%$, associated with loss of surface water (adsorbed water). Another endothermic peak, at $695{ }^{\circ} \mathrm{C}$ (loss of approximately $6 \%$ mass), was related to calcium carbonate degradation, as observed in the X-ray diffractogram of this sample (Fig. 2). In general, carbonate decomposition occurred near $900{ }^{\circ} \mathrm{C}[23,24]$; however, the lower value observed was associated with the size of the particles, i.e., the smaller the size, the lower the decomposition temperature. Above $700{ }^{\circ} \mathrm{C}$, other reactions occurred without change in mass, and therefore, there was no degradation of the material.

Since the longer synthesis time (MAH) resulted in a material with lower carbonate volume, the thermal treatments for phase crystallization were performed only with the sample synthesized for $160 \mathrm{~min}$. Small amounts of this sample were heated at four different temperatures $\left(700,800,900\right.$ and $\left.1000{ }^{\circ} \mathrm{C}\right)$ for one hour and analyzed by XRD 


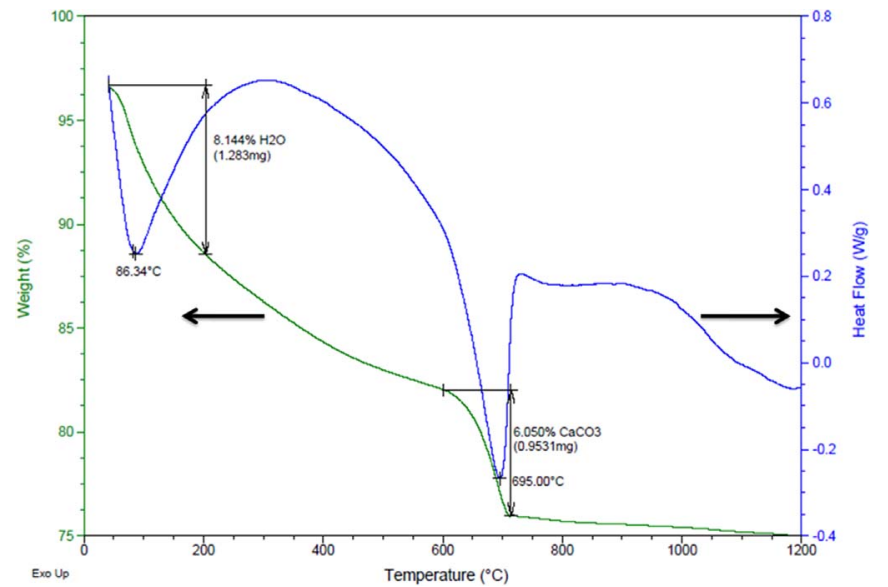

Fig. 3. Thermogram of the $\mathrm{CaZrO}_{3}$ sample synthesized for $20 \mathrm{~min}$.

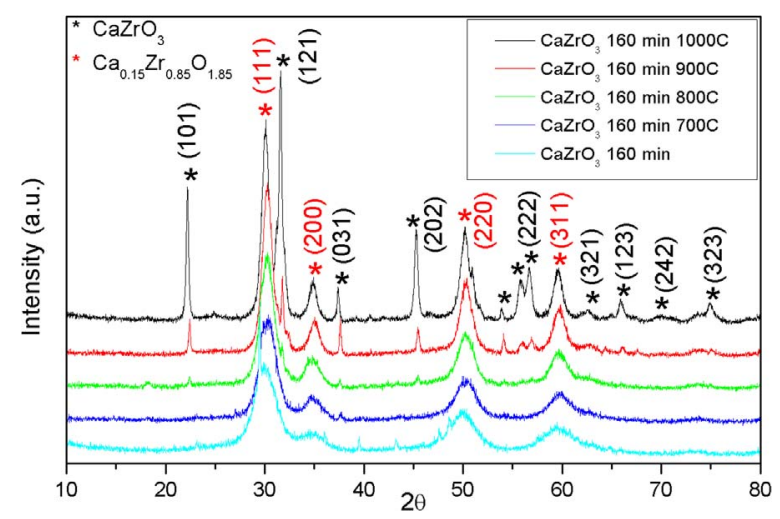

Fig. 4. XRD of the $\mathrm{CaZrO}_{3}$ samples synthesized by MAH for $160 \mathrm{~min}$ (a) without heating, and heated at (b) $700{ }^{\circ} \mathrm{C}$, (c) $800{ }^{\circ} \mathrm{C}$, (d) $900{ }^{\circ} \mathrm{C}$ and (e) $1000{ }^{\circ} \mathrm{C}$, for $1 \mathrm{~h}$.

(Fig. 4). The sample heated at $700{ }^{\circ} \mathrm{C}$ showed little change in the diffractogram. The XRD peaks became more intense and sharper, especially those near $30^{\circ}$. In this sample, the carbonate fine peaks were not observed, confirming the thermal analysis results (Fig. 3), i.e., calcium carbonate decomposition occurred at this temperature. The diffractogram showed that in the samples heated at 800 and $900{ }^{\circ} \mathrm{C}$, the initial growth of the calcium zirconate (lakargite, PDF 35-790 - $\mathrm{CaZrO}_{3}$ ) and non-stoichiometric calcium-zirconium oxide phases (PDF 26-341 $\mathrm{Ca}_{0.15} \mathrm{Zr}_{0.85} \mathrm{O}_{1.85}$ ) was observed, but that they did not crystallize completely. The larger diffraction peaks, close to $30^{\circ}, 35^{\circ}, 50^{\circ}$ and $60^{\circ}(2 \theta)$ are characteristic of the non-stoichiometric calcium-zirconium oxide phase, with cubic unit cell, while the sharp ones are characteristic of the orthorhombic calcium zirconate phase. Therefore, with these synthesis conditions and heating, non-stoichiometric calcium-zirconium oxide nanoparticles were predominantly formed and well-crystallized calcium zirconate, characterized by fine XRD peaks, was less evident. However, as the heat treatment temperature was increased $\left(1000{ }^{\circ} \mathrm{C}\right)$, there was an increase in the $\mathrm{CaZrO}_{3}$ phase over the non-stoichiometric phase.

The SEM images for the sample synthesized for $160 \mathrm{~min}$ and treated at $1000{ }^{\circ} \mathrm{C}$ are shown in Fig. 5. The images show agglomerates (micrometric) with high roughness and no defined shapes (Fig. 5 (a)) and with nanometric particles adhered to their surface (Fig. 5 (a)-(d)), which is usually observed in the growth of perovskite crystals [25]. The observation of agglomerate particles with undefined morphology indicated that one hour of heat treatment was not sufficient for phase morphological evolution [17]. The X-ray diffractograms showed wide peaks, especially for the non-stoichiometric phase, indicating smaller particles for this phase. These images showed different morphologies compared to those for other synthesis routes of $\mathrm{CaZrO}_{3}[5,6]$, which

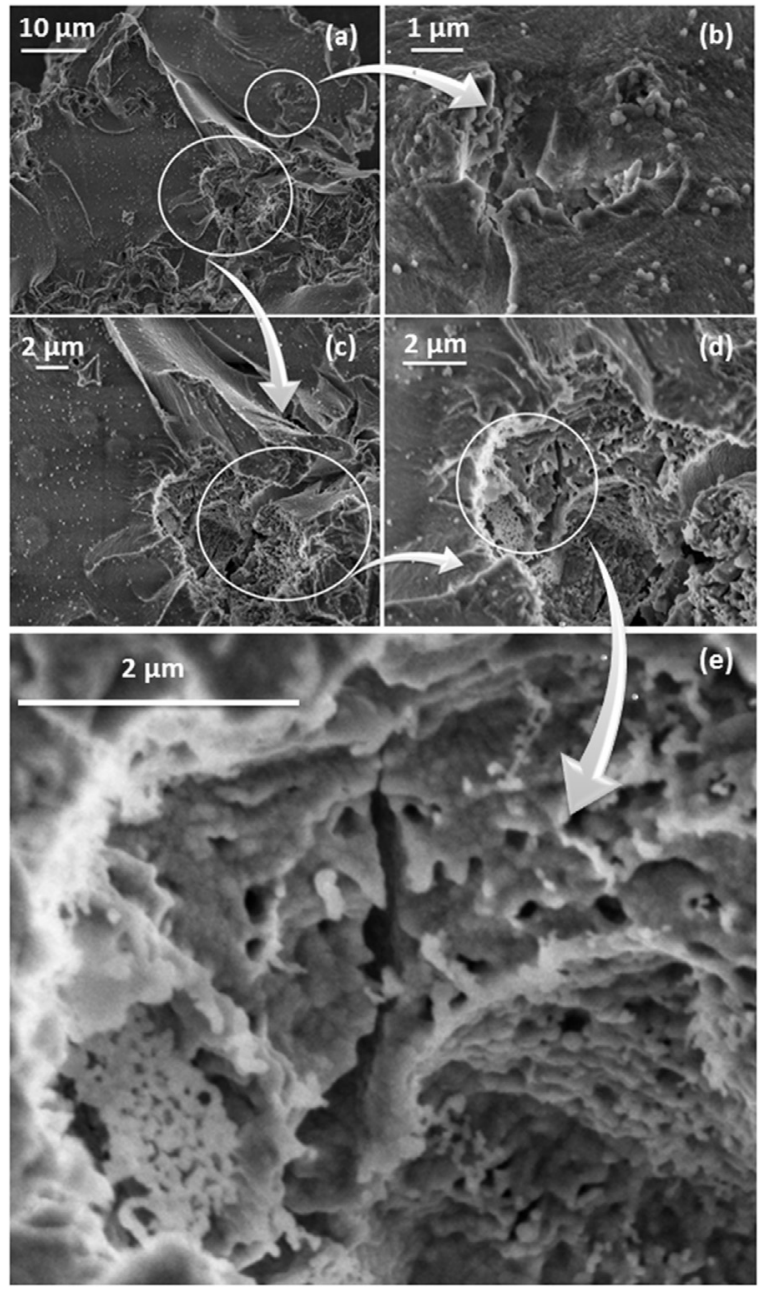

Fig. 5. SEM images of the $\mathrm{CaZrO}_{3}$ sample synthesized by MAH for $160 \mathrm{~min}$ and heated at $1000^{\circ} \mathrm{C}$ for $1 \mathrm{~h}$.

although they showed that the samples were composed of porous agglomerates, there were smaller particles with defined morphology. This characteristic is observed in the enlargement in Fig. 5(d), which shows that the micrometric particle analyzed was formed by the agglomeration of nanometric particles, apparently spherical and organized to give a porous microstructure (Fig. 5(e)).

Huang et al. [17] and other authors [26,27] report that a longer heating time is more efficient than a higher temperature in the crystallization of zirconates. Accordingly, a sample synthesized for $160 \mathrm{~min}$ by MAH was heated at $1000^{\circ} \mathrm{C}$ for $6 \mathrm{~h}$ (Fig. $6-(\mathrm{I})$ ). For this longer heating time, there was a slight improvement in the crystallization of the two phases, which showed more defined XRD peaks. Although this slight improvement in the intensity and resolution of the doublets, at $30^{\circ}$ and between $50^{\circ}$ and $60^{\circ}(2 \theta)$ confirmed a better phase crystallization in the sample treated for $6 \mathrm{~h}$, these changes were not as substantial as those observed by Huang et al. [17].

For the sample treated at $1200{ }^{\circ} \mathrm{C}$ for $1 \mathrm{~h}$, the X-ray diffraction pattern (Fig. 6 - (II)) showed the existence of two well-ordered phases, with sharp and more intense diffraction peaks. This showed that the higher temperature was more effective than longer heat treatment time (Fig. 6 - (I)) in the crystallization process for this synthesis method. For this sample, structure refinement was performed using the Rietveld method (Fig. 7). From the refinement, the lattice parameters and percentage of formed phases were obtained. The mean crystallite size was obtained by the Scherrer equation using XPowder software (Table 1).

Refinement showed good values of convergence parameters between the points observed and calculated $\left(\chi^{2}=1.785\right.$, wRp $=8.44 \%$, 

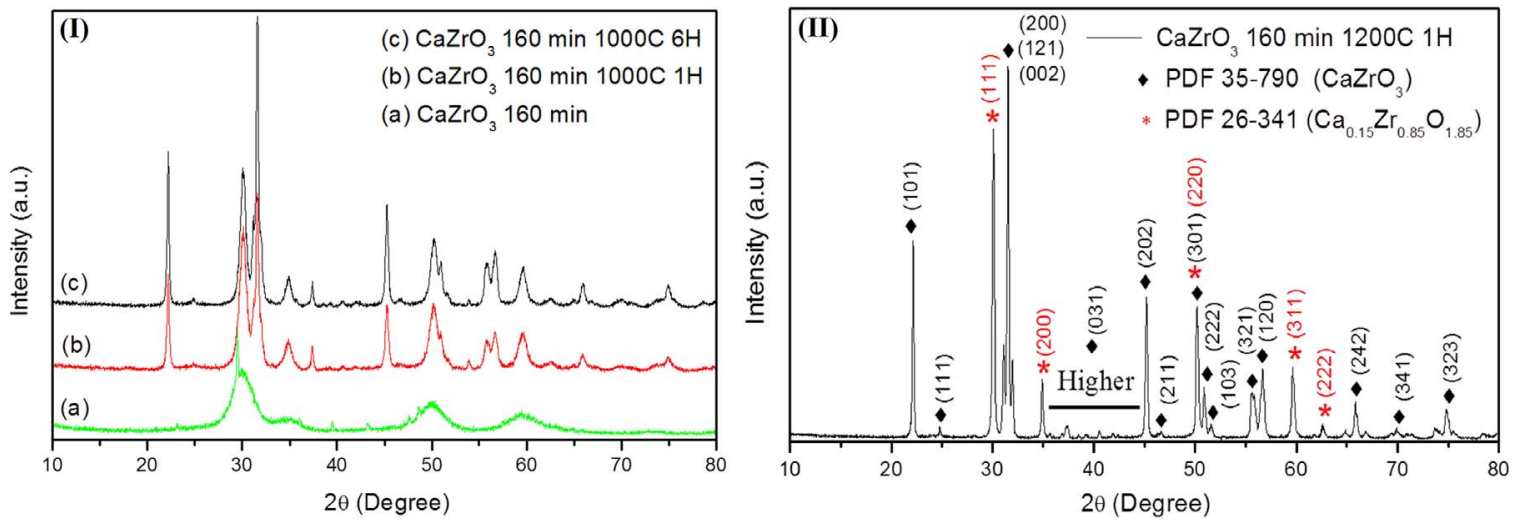

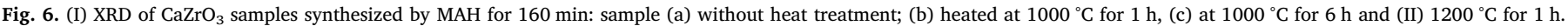

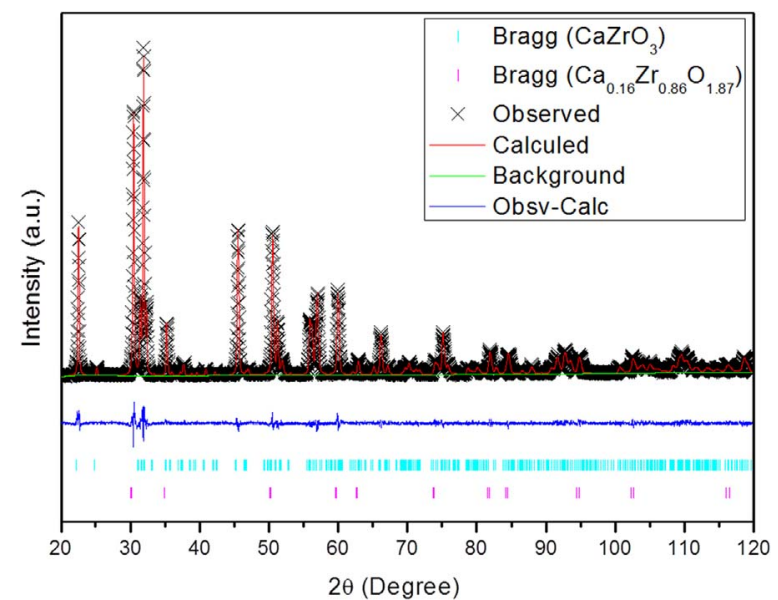

Fig. 7. Rietveld structure refinement diffractogram of the $\mathrm{CaZrO}_{3}$ sample synthesized by MAH for $160 \mathrm{~min}$ and heated at $1200{ }^{\circ} \mathrm{C}$ for $1 \mathrm{~h}$.

$\left.\mathrm{R}\left(\mathrm{F}^{2}\right)=3.67 \%\right)$. The percentages of the orthorhombic calcium zirconate and non-stoichiometric calcium-zirconium oxide cubic phases were $65 \%$ and $35 \%$, respectively. The cubic phase stoichiometry was determined to be $\mathrm{Ca}_{0.16} \mathrm{Zr}_{0.86} \mathrm{O}_{1.87}$. The diffractograms demonstrated that with heat treatment, the non-stoichiometric phase was initially more crystalline, i.e., larger crystallites, with more intense diffraction peaks. According to the average crystallite size before (4 and $52 \mathrm{~nm}$ ) and after $\left(76\right.$ and $75 \mathrm{~nm}$ ) heat treatment at $1200{ }^{\circ} \mathrm{C}$, zirconate crystallization rate was higher than that of non-stoichiometric oxide, during heat treatment. Both phases reached approximately the same final crystallite sizes, as observed in Fig. 6 - (II) by the peak width of each phase. Comparing the calculated lattice parameters with those of the reference diffractograms (PDF), there was a slight increase in unit cell for the two phases.

The Raman spectroscopy results of the heated sample at $1200{ }^{\circ} \mathrm{C}$ are shown in Fig. 8 and Table 2, confirming the X-ray diffraction data. The most evident and intense vibration modes were those referring to the $\mathrm{CaZrO}_{3}$ phase. Non-stoichiometric phase vibration modes, such as those peaking at 141 and $460 \mathrm{~cm}^{-1}$, coincided with those of the calcium

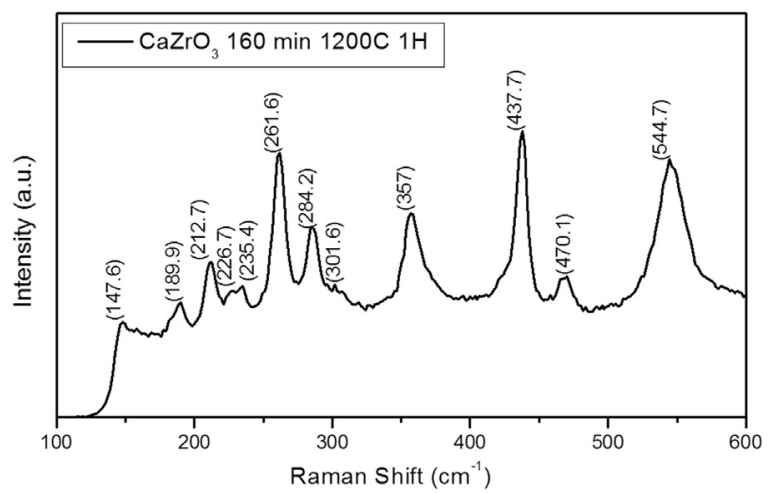

Fig. 8. Raman spectrum of the $\mathrm{CaZrO}_{3}$ sample synthesized by MAH for $160 \mathrm{~min}$ and heated at $1200{ }^{\circ} \mathrm{C}$ for $1 \mathrm{~h}$.

Table 2

Comparison of the wave numbers obtained for the $\mathrm{CaZrO}_{3}$ sample synthesized by MAH for $160 \mathrm{~min}$ and heated at $1200{ }^{\circ} \mathrm{C}$ for $1 \mathrm{~h}$ with those of reference 29 .

\begin{tabular}{lll}
\hline $\mathrm{CaZrO}_{3}$ Sample $\left(\mathbf{c m}^{-\mathbf{1}}\right)$ & Orera et al. [29] $\left(\mathbf{c m}^{-\mathbf{1}}\right)$ & Assigned Mode \\
\hline $\mathbf{1 4 7 . 6}$ & 145 & $\left(A_{g}\right)$ Network Mode \\
$\mathbf{1 8 9 . 9}$ & 190 & $\left(B_{2 g}\right) \mathrm{Zr}-\mathrm{O}$ Flexion \\
$\mathbf{2 1 2 . 7}$ & 212 & $\left(B_{2 g}\right) \mathrm{Zr}-\mathrm{O}$ Flexion \\
$\mathbf{2 2 6 . 7}$ & 227 & $\left(B_{1 g} B_{3 g}\right) \mathrm{Zr}-\mathrm{O}$ Flexion \\
$\mathbf{2 3 5 . 4}$ & 234 & $\left(B_{2 g}\right) \mathrm{Zr}-\mathrm{O}$ Flexion \\
$\mathbf{2 6 1 . 6}$ & 262.5 & $\left(A_{g}\right) \mathrm{Zr}-\mathrm{O}$ Flexion \\
$\mathbf{2 8 4 . 2}$ & 286.5 & $\left(A_{g}\right) \mathrm{Zr}-\mathrm{O}$ Flexion \\
$\mathbf{3 0 1 . 6}$ & 305 & $\left(B_{1 g}\right.$ or $\left.B_{3 g}\right) \mathrm{Zr}-\mathrm{O}$ Twist \\
$\mathbf{3 5 7}$ & 358 & $\left(A_{g}\right) \mathrm{Twist}$ \\
- & 418 & $\left(B_{2 g}\right) \mathrm{Twist}$ \\
$\mathbf{4 3 7 . 7}$ & 439 & $\left(A_{g}+B_{1 g}\right)$ Twist \\
$\mathbf{4 7 0 . 1}$ & 469 & $\left(B_{2 g}\right) \mathrm{Zr}-\mathrm{O}$ Stretching \\
$\mathbf{5 4 4 . 7}$ & 543 & $\left(A_{g}+B_{2 g}\right) \mathrm{Zr}-\mathrm{O}$ Stretching \\
- & 547 & $\left(B_{1 g}+B_{3 g}\right) \mathrm{Zr}-\mathrm{O}$ Stretching \\
\hline
\end{tabular}

zirconate phase [28]. The other peaks were very weak and overlapped by calcium zirconate vibrational modes. According to Rosa et al. [13], the frequencies near 141 and $185 \mathrm{~cm}^{-1}$ correspond to the $A_{g}$ and $B_{2 g}$

Table 1

Rietveld structure refinement data of the $\mathrm{CaZrO}_{3}$ sample synthesized by MAH for 160 min and heated at $1200{ }^{\circ} \mathrm{C}$ for $1 \mathrm{~h}$.

\begin{tabular}{|c|c|c|c|c|c|c|c|}
\hline \multicolumn{2}{|c|}{ Phase } & Structure & a (̊̊) & b (Å) & c (̊̊) & Weight \% (\%wt) & Average crystallite size (nm) \\
\hline \multicolumn{2}{|c|}{$\mathrm{CaZrO}_{3}$} & Orthorhombic & 5.599 & 8.019 & 5.752 & $65 \%$ & 76 \\
\hline \multicolumn{2}{|c|}{$\mathrm{Ca}_{0.16} \mathrm{Zr}_{0.86} \mathrm{O}_{1.87}$} & Cubic & 5.139 & 5.139 & 5.139 & $35 \%$ & 75 \\
\hline \multirow[t]{2}{*}{ PDF } & $\mathrm{CaZrO}_{3}$ & Orthorhombic & 5.593 & 8.010 & 5.756 & - & - \\
\hline & $\mathrm{Ca}_{0.15} \mathrm{Zr}_{0.85} \mathrm{O}_{1.85}$ & Cubic & 5.135 & 5.135 & 5.135 & - & - \\
\hline
\end{tabular}

* Powder Diffraction Files: 35-790 $\left(\mathrm{CaZrO}_{3}\right)$ and 26-341 $\left(\mathrm{Ca}_{0.15} \mathrm{Zr}_{0.85} \mathrm{O}_{1.85}\right)$. 


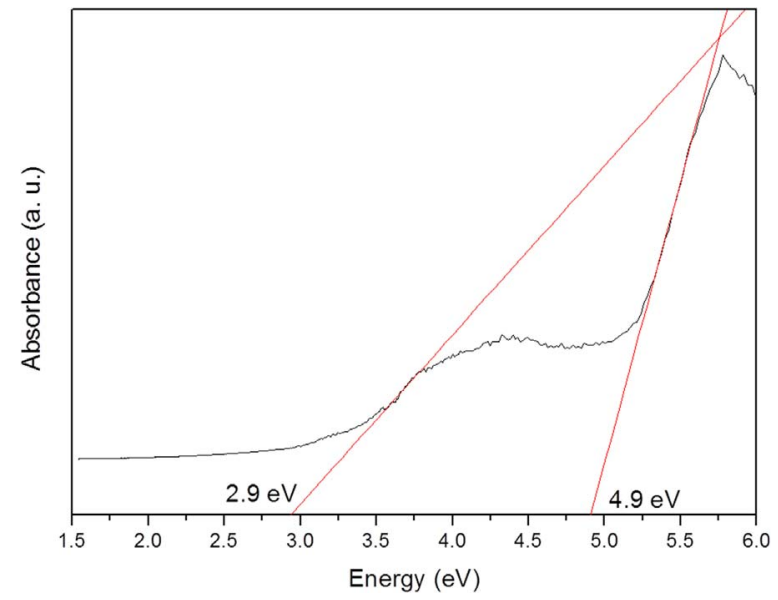

Fig. 9. UV-Vis absorption spectrum of the $\mathrm{CaZrO}_{3}$ sample synthesized by $\mathrm{MAH}$ for $160 \mathrm{~min}$ and heated at $1200{ }^{\circ} \mathrm{C}$ for $1 \mathrm{~h}$.

vibrational modes of the $\mathrm{Zr}-\mathrm{O}$ bond, respectively. All other torsion modes, stretching and bending, peaked approximately in the same regions as the references [13-29]. The differences seen at the maximum point of these bands can be related to the average crystallite size of each sample, because the FWHM of Raman bands, in general, is inversely proportional to the average crystallite size [30]. On the other hand, the non-stoichiometric calcium-zirconium phase may contain structural defects due to oxygen vacancies, for example, which may change the bonding energy between $\mathrm{Zr}$ and $\mathrm{O}$ atoms and also the cluster $\left[\mathrm{ZrO}_{6}\right]$ symmetry, which can result in the Raman mode shift. According to André [2], defects are related to short-, medium- and long-distance structural order-disorder, which in turn may alter the material electronic structure and surfaces and interfaces as well. As a consequence, changes in Raman band position and $\mathrm{E}_{\text {gap }}$ may occur, for example. Also, according to $\mathrm{Li}$ et al.[31], the bands at 149,269 and $312 \mathrm{~cm}^{-1}$ are characteristic of the tetragonal $\mathrm{ZrO}_{2}$ phase. However, the spectrum in Fig. 9 showed the absence of these bands, confirming the finding that the non-stoichiometric phase $\left(\mathrm{Ca}_{0.16} \mathrm{Zr}_{0.86} \mathrm{O}_{1.87}\right)$, whose substitution occurs at the $\mathrm{Ca} / \mathrm{Zr}$ site, has cubic symmetry, as identified by XRD.

The optical $E_{\text {gap }}$ of the $\mathrm{CaZrO}_{3}$ sample synthesized by MAH for $160 \mathrm{~min}$ and heated at $1200{ }^{\circ} \mathrm{C}$ for $1 \mathrm{~h}$ was determined using the Wood and Tauc method [22], considering an indirect transition. Fig. 9 shows the absorption spectrum versus photon energy for this sample. Two absorption regions were observed, for which two different $\mathrm{E}_{\text {gap }}$ were estimated, 2.9 and $4.9 \mathrm{eV}$. These values were attributed to the gap of the non-stoichiometric calcium-zirconium and $\mathrm{CaZrO}_{3}$ phases, respectively. In the work of Rosa et al. [13], the experimental $E_{\text {gap }}$ value of the pure $\mathrm{CaZrO}_{3}$ phase was $5.7 \mathrm{eV}$, while André [2] reported a value of $3.8 \mathrm{eV}$, also for a pure phase, where the polymeric precursor method was used in both cases. Stoch et al. [32] found $E_{\text {gap }}$ values on the order of $4.1 \mathrm{eV}$ for $\mathrm{CaZrO}_{3}$, prepared by melting in an electric arc and the standard solid state reaction method. These results showed the influence of the synthesis method and suggested that the coexistence of nonstoichiometric calcium-zirconium and $\mathrm{CaZrO}_{3}$ phases significantly alter the band structure configuration of each one. $\mathrm{ZrO}_{2}$, for example, may have its $E_{\text {gap }}$ changed by dopants, as observed by Lovisa [33]. According to the author, the controlled doping of $\mathrm{ZrO}_{2}$ with $\mathrm{Tb}$, Eu or Tm, associated with the calcination conditions, can alter $\mathrm{E}_{\text {gap }}$ from 2.8 to $4.8 \mathrm{eV}$. This author contends that the decrease in gap energy depends on structural ordering, that is, the lower the $\mathrm{E}_{\text {gap }}$ value, the greater the number of intermediate levels in the band gap. In this context, for the non-stoichiometric calcium-zirconium phase, the $\mathrm{Ca} / \mathrm{Zr}$ substitution and the absence of oxygen in the lattice leads to medium-range defects and may induce destabilization of its electronic structure and alteration in $\mathrm{E}_{\text {gap }}$. In addition, these changes in $\mathrm{E}_{\text {gap }}$, compared to those in the literature for the two phases, may be related to the nanometric particle size and interface effects between them.

\section{Conclusions}

$\mathrm{CaZrO}_{3}$ samples were obtained by a new synthesis route: nucleation using the MAH method and crystallization by heat treatment. The results showed that the crystallization process of the $\mathrm{CaZrO}_{3}$ phase started with heating at $800{ }^{\circ} \mathrm{C}$, together with the crystallization of the nonstoichiometric calcium-zirconium oxide. After heat treatment at $1200{ }^{\circ} \mathrm{C}$, the sample consisted of $65 \%$ orthorhombic $\mathrm{CaZrO}_{3}$ phase and $35 \%$ non-stoichiometric cubic phase, both with high structural ordering, according to XRD data and structure refinement. SEM images showed that after heat treatment at $1000{ }^{\circ} \mathrm{C}$, the samples consisted of micrometric particles formed by the agglomeration of nanometric particles. Also, some nanoparticles were found to be adhered to the surface of larger particles. The material synthesized apparently exhibited sensitivity to surface water, as shown by the thermal analysis results, which might have been improved (relative to the single-phase $\mathrm{CaZrO}_{3}$ materials) due to its coexistence with the non-stoichiometric phase and its consequent increase in surface area. The UV-Vis spectrum showed two absorption regions, for which the gap energy values of 2.9 and $4.9 \mathrm{eV}$ were estimated, and attributed to the non-stoichiometric calcium-zirconium oxide and $\mathrm{CaZrO}_{3}$ phases, respectively. These values are smaller than those obtained by other synthesis routes. Variations in the $\mathrm{E}_{\text {gap }}$ values for the two phases, compared to the literature, may be associated with structural disorder and with the interface between the nanometric particles of both phases.

\section{Acknowledgements}

The authors would like to thank Dr. A. Leyva (USA) for English editing of the manuscript.

This work was supported by FAPESP/CEPID [2013/07296-2], CNPq [573636/2008-7] and CAPES through a scholarship (PhD - POSMAT) awarded to W. D. Macedo Jr.

\section{References}

[1] E.V. Galuskin, V.M. Gazeev, T. Armbruster, A.E. Zadov, I.O. Galuskina, N.N. Pertzev, P. Dzierzanowski, M. Kadiyski, A.G. Gurbanov, R. Wrzalik, A. Winiarski, Lakargiite $\mathrm{CaZrO}_{3}$ : a new mineral of the perovskite group from the North Caucasus, Kabardino-Balkaria, Russia, Am. Mineral. 93 (2008) 1903-1910.

[2] R.S. André, Zirconato de Cálcio: Um Estudo Para Aplicação Como Sensor de Umidade Relativa. (Calcium Zirconate: A Study for Application as Relative Humidity Sensor) (Master's dissertation), Federal Universityof São Carlos, São Carlos, São Paulo, Brazil, 2013.

[3] V.M. Longo, A.T. Figueiredo, A.B. Campos, J.W. Espinosa, A.C. Hernandes, C.A. Taft, J.R. Sambrano, J.A. Varela, E. Longo, Different origins of green-light photoluminescence emission in structurally ordered and disordered powders of calcium molibdate, J. Phys. Chem. A 112 (2008) 8920.

[4] X. Yang, Q. Li, R. Liu, B. Liu, S. Jiang, K. Yang, J. Liu, Z. Chen, B. Zou, T. Cui, B. Liu, A novel pressure-induced phase transition in $\mathrm{CaZrO}_{3}$, CrystEngComm. 16 (2014) 4441.

[5] R.S. André, S.M. Zanetti, J.A. Varela, E. Longo, Synthesis by a chemical method and characterization of $\mathrm{CaZrO}_{3}$ powders: potential application as humidity sensors, Ceram. Int. 40 (2014) 16627-16634.

[6] M. Dudek, E.D. Ciesla, Some observations on synthesis and electrolytic properties of nonstoichiometric calcium zirconate, J. Alloy. Compd. 475 (2009) 846.

[7] C.C. Wang, S.A. Akbar, W. Chen, J.R. Schorr, High-temperature thermistors based on yttria and calcium zirconate, Sens Actuators A 58 (1997) 237-243.

[8] D. Janke, Oxygen probes based on calcia-doped hafnia or calcium zirconate for use in metallic melts, Metall. Mater. Trans. B 13 (1982) 227-235.

[9] A.H. Setiawan, J.W. Fergus, Preparation and characterization of In-doped $\mathrm{CaZrO}_{3}$ as the electrolyte in hydrogen sensors for use in molten aluminum, Ceram. Trans. 130 (2002) 47-56.

[10] T. Yajima, K. Koide, H. Takai, N. Fukatsu, H. Iwahara, Application of hydrogen sensor using proton conductive ceramics as a solid electrolyte to aluminum casting, Solid State Ion. 79 (1995) 333-337.

[11] Y. Du, Z.P. Jin, P.Y. Huang, Thermodynamic calculation of the zirconia calcia system, J. Am. Ceram. Soc. 75 (1992) 3040-3048.

[12] S.C. Hwang, G.M. Choi, The effect of cation nonstoichiometry on the electrical conductivity of aceptor-doped $\mathrm{CaZrO}_{3}$, Solid State Ion. 177 (2006) 3099.

[13] I.L.V. Rosa, M.C. Oliveira, M. Assis, M. Ferrer, R.S. André, E. Longo, M.F.C. Gurgel, A theoretical investigation of the structural and electronic properties of 
orthorhombic $\mathrm{CaZrO}_{3}$, Ceram. Int. 41 (2015) 3069-3074.

[14] J. Han, Z. Wen, J. Zhang, et al., Synthesis and characterization of proton conductive $\mathrm{CaZr}_{0.90} \mathrm{In}_{0 .}{ }_{10} \mathrm{O}_{3}$-delta by a citric acid complexation method, Fusion Eng. Des. 85 (2010) 2100.

[15] A.L. Ibiapino, L.P. Figueiredo, Síntese e caracterização de $\mathrm{CaZrO}_{3}$ e $\mathrm{BaZrO}_{3}$ nanoestruturados. (Synthesis and characterization of nanostructured $\mathrm{CaZrO}_{3}$ and $\mathrm{BaZrO}_{3}$ ), Quim. Nova. 36 (2013) 762-767.

[16] M.R. Nadler, E.S. Fitzsimmons, Preparation and properties of calcium zirconate, J. Am. Ceram. Soc. 38 (1955) 214-215.

[17] Z. Huang, X. Deng, J. Liu, S. Zhang, Preparation of $\mathrm{CaZrO}_{3}$ powders by a microwave-assisted molten salt method, J. Ceram. Soc. Jpn. 124 (2016) 593-596.

[18] S. Komamerni, R. Roy, Q.H. Li, Microwave-hydrothermal synthesis of ceramic powders, Mater. Res. Bull. 27 (1992) 1393-1405.

[19] T.A. Blank, L.P. Eksperiandova, K.N. Belikov, Recent trends of ceramic humidity sensors development: a review, Sens. Actuators B 228 (2016) 416-442.

[20] A.E. Souza, S.R. Teixeira, E. Longo, Titanatos: Fotoluminescência e Crescimento de Nanopartículas. (Titanates: Photoluminescence and Nanoparticles Growth), first ed., Saarbrüker, Germany, 2015.

[21] I.J. Langford, A.J.C. Wilson, Scherrer after sixty years: a survey and some new results in the determination of crystallite size, J. Appl. Crystallogr. 11 (1978) 102-113.

[22] D.L. Wood, J. Tauc, Weak absorption tails in amorphous semiconductors, Phys. Rev. B 5 (1972) 3144-3151.

[23] G. Narsimhan, Thermal decomposition of calcium carbonate, Chem. Eng. Sci. 16 (1961) 7-20.

[24] S.F.S. Mohamad, S. Mohamad, Z. Jemaat, Study of calcination condition on the composition of calcium carbonate in waste cockle shell to calcium oxide using thermal gravimetric analysis, J. Eng. Appl. Sci. (Faisalabad Pak.) 11 (2016) 9917-9921.

[25] K. Huang, L. Yuan, S. Feng, Crystal facet tailoring art in perovskite oxides, Inorg. Chem. Front. 2 (2015) 965-981.

[26] S. Kanagesan, M. Hashim, S. Jesurani, T. Kalaivani, I. Ismail, M.S.E. Shafie, Particle morphology and magnetic properties of $\mathrm{Ba}_{0 .}{ }_{5} \mathrm{Sr}_{0 .}{ }_{5} \mathrm{Fe}_{12} \mathrm{O}_{19}$ powder calcined conventionally and by microwave heating, J. Alloy. Compd. 543 (2012) 49-52.

[27] W.J. Park, M.K. Jung, T. Masaki, S.M. Im, D.H. Yoon, Characterization of $\mathrm{YVO}_{4}: \mathrm{Eu}^{3+}, \mathrm{Sm}^{3+}$ red phosphor quick synthesized by microwave rapid heating method, Mater. Sci. Eng. B 146 (2008) 95-98.

[28] A.P. Naumenko, N.I. Berezovska, M.M. Biliy, O.V. Shevchenko, Vibrational analysis and Raman spectra of tetragonal zirconia, Phys. Chem. Solid State. 9 (2008) $121-125$.

[29] V.M. Orera, C. Pecharromán, J.I. Peña, R.I. Merino, C.J. Serna, Vibrational spec troscopy of $\mathrm{CaZrO}_{3}$ single crystals, J. Phys.: Condens. Matter. 10 (1998) 7501.

[30] J.R. Ferraro, K. Nakamoto, C.W. Brown, Introductory Raman Spectroscopy, second ed., Elsevier Science, USA, 2003.

[31] C. Li, M. Li, UV Raman spectroscopy study on the phase transformation of $\mathrm{ZrO}_{2}$ $\mathrm{Y}_{2} \mathrm{O}_{3}-\mathrm{ZrO}_{2}$ and $\mathrm{SO}_{4}{ }^{2-} / \mathrm{ZrO}_{2}$, J. Raman Spectrosc. 33 (2002) 301-308.

[32] P. Stoch, J. Szczerba, J. Lis, D. Madej, Z. Pedzich, Crystal structure and ab initio calculations of $\mathrm{CaZrO}_{3}$, J. Eur. Ceram. Soc. 32 (2012) 665-670.

[33] X.L. Lovisa, Propriedade Fotoluminescente da $\mathrm{ZrO} 2: \mathrm{Tb}^{+3}, \mathrm{Eu}^{+3}, \mathrm{Tm}^{+3}$ Obtida Pelo Método de Polimerização de Complexos. (Photoluminescence Properties of $\mathrm{ZrO}_{2}$ : $\mathrm{Tb}^{+3}, \mathrm{Eu}^{+3}, \mathrm{Tm}^{+3}$ Obtained by polymerization of complexes) (Master's dissertation), Federal Universityof Rio Grande do Norte, Natal, Rio Grande do Norte, Brazil, 2013. 